\title{
INVESTIGATION OF STRUCTURE AND PROPERTIES OF THERMAL COATINGS OF WC-Co-Cr SYSTEM PRODUCED BY HIGH-VELOCITY METHODS OF SPRAYING
}

\author{
Yu.S. BORISOV, E.A. ASTAKHOV, A.P. MURASHOV, A.P. GRISHCHENKO, \\ N.V. VIGILYANSKAYA and M.V. KOLOMYTSEV \\ E.O. Paton Electric Welding Institute, NASU \\ 11 Bozhenko Str., 03680, Kiev, Ukraine. E-mail: office@paton.kiev.ua
}

\begin{abstract}
Spraying of coatings of $\mathrm{WC}-9 \mathrm{Co}-4 \mathrm{Cr}$ powder was performed by high-velocity procedures of thermal spraying, using the methods of detonation, supersonic air-gas plasma (SAGP) and oxy-fuel HVOF spraying. Microstructure and properties of produced coatings were investigated. Analysis of results of the coating structure examination showed that during spraying with these methods the dense coatings are formed, consisting of inclusions of tungsten carbide, uniformly distributed in $\mathrm{Co}-\mathrm{Cr}$ matrix. Porosity of coatings is less than $1 \%$. Microhardness of SAGP- and HVOF-sprayed coatings is 11.0-11.7 GPa. As to the values of microhardness these coatings are superior to those of the galvanic chromium (10 GPa). Microhardness of the detonation coating is $8.5 \mathrm{GPa}$. The cause of decrease in hardness of the detonation coating is a partial loss of carbon and appearance of oxide inclusions in it, that is caused by the oxidizing medium of the detonation products. By the complex of characteristics of hardness, adhesion strength (more than $50 \mathrm{MPa}$ ) and porosity the coatings of $\mathrm{WC}-9 \mathrm{Co}-4 \mathrm{Cr}$ system, sprayed by SAGP and HVOF methods, are advantageous as compared with the galvanic chrome-plating. Among the investigated methods of high-velocity thermal spraying of coatings of $\mathrm{WC}-9 \mathrm{Co}-4 \mathrm{Cr}$ system the SAGP method is characterized by the highest efficiency (15 kg/h). 16 Ref., 2 Tables, 2 Figures.
\end{abstract}

Keywords: thermal spraying, coating, galvanic chrome-plating, detonation spraying, supersonic air-gas plasma spraying, high-velocity oxy-fuel coating of WCCo-Cr system, microstructure, porosity, microhardness

The high-velocity methods of spraying allow widening greatly the possibility of traditional gasthermal spraying (GTS) of coatings used for protection of parts from wear and corrosion. Due to reducing the time of particles staying in the hightemperature flow and decreasing their overheating in high-velocity methods of GTS the oxidation of particles and, respectively, coating is reduced. At the same time, due to the high rate of particles the margin of their kinetic energy is increased, that leads to the increase in coating density and strength of coating adhesion with the base [1]. The typical peculiarities of coatings, produced by the high-velocity spraying, is a low porosity (less than $1.5 \%$ ) and retaining of chemical composition of the initial powder, as well as high strength of adhesion (more than 50$70 \mathrm{MPa}$ ). The gas-thermal high-velocity methods of coating producing include the methods of detonation, supersonic air-gas plasma (SAGP) and high-velocity oxy-fuel (HVOF) spraying. The rate of particles in spraying is up to $1000 \mathrm{~m} / \mathrm{s}$ at detonation spraying, $500-1000 \mathrm{~m} / \mathrm{s}$ at SAGP and up to $800 \mathrm{~m} / \mathrm{s}$ at HVOF spraying [2].

One of the most spread coatings in GTS is the coatings on the tungsten carbide base, which are widely used in different branches of industry for increase in resistance of parts against the wear and corrosion. High wear resistance of gas-thermal WC-Co coatings is provided by combination of $\mathrm{WC}$ as a hard component and Co as a ductile binder. In case of spraying of $\mathrm{WC}-\mathrm{Co}$ coatings the high-velocity methods are preferred in comparison with other GTS methods, as the higher rates and lower temperatures of the powder particles decrease the degree of $\mathrm{WC}$ decomposition, thus preventing the decrease in hardness and wear resistance [3]. For spraying, WC-Co powders are used with 6-17\% Co content, produced by different methods $[4,5]$. To increase the resistance of $\mathrm{WC}-\mathrm{Co}$ coatings against corrosion, $\mathrm{WC}-\mathrm{Co}$ powders are alloyed with chromium, as $\mathrm{Co}-\mathrm{Cr}$ matrix provides the high resistance against corrosion as compared with WC-Co materials. The chromium content in powders is 4$8 \%$ (WC-10Co-4Cr; WC-6Co-8Cr) [4]. Depending on powder composition, type of equipment and conditions of spraying, the microhard- 


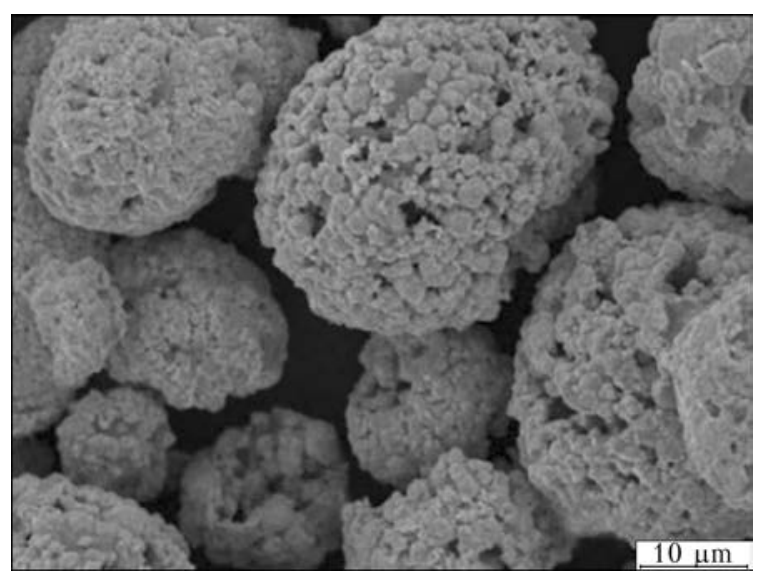

Figure 1. Appearance of $\mathrm{WC}-9 \mathrm{Co}-4 \mathrm{Cr}$ powder

ness of produced $\mathrm{WC}-\mathrm{Co}$ coatings is $6-12 \mathrm{GPa}$ at detonation spraying [6, 7], 10-15 $\mathrm{GPa}$ at SAGP [8, 9] and HVOF spraying [10, 11]. Porosity of these coatings, produced by high-velocity methods, usually does not exceed $1.5 \%$.

The high-velocity spraying of coatings on tungsten carbide base is one of the alternatives to the galvanic chrome-plating. Except such advantages as producing coatings, characterized by the resistance against wear, corrosion, erosion, GTS, unlike the technology of the chrome-plating, it is ecologically clean process, whereas hexivalent chromium, main element of electrolytes of chrome-plating, is a carcinogen, hazardous for health even at low concentrations [12]. $\mathrm{WC}^{-} \mathrm{Co}^{-}$ $\mathrm{Cr}$ coatings have a high hardness, low coefficient of friction, and their wear resistance, as compared with hard chromium, is 3-5 times higher [13]. $\mathrm{WC}-\mathrm{Co}-\mathrm{Cr}$ coatings are not inferior to hard chromium by the corrosion resistance due to presence of chromium [14, 15]. Thermal coatings of tungsten carbide as an alternative to the galvanic chrome-plating found the wide application in aircraft industry on parts of hydraulic drives and landing gears [16].

Table 1. Modes of spraying $\mathrm{WC}-9 \mathrm{Co}-4 \mathrm{Cr}$ coatings

\begin{tabular}{||l|c|c|c||}
\hline \multirow{2}{*}{$\begin{array}{c}\text { Consumption of working gas, } \\
\mathrm{m}^{3} / \mathrm{h}\end{array}$} & \multicolumn{3}{|c||}{ Spraying method } \\
\cline { 2 - 4 } & Detonation & SAGP & HVOF \\
\hline $\mathrm{C}_{3} \mathrm{H}_{8}$ & 0.42 & - & - \\
\hline $\mathrm{O}_{2}$ & 1.7 & - & 15 \\
\hline Air & 0.53 & 26 & 36 \\
\hline $\mathrm{CH}_{4}$ & - & - & 7.2 \\
\hline $\mathrm{N}_{2}$ & - & - & 0.18 \\
\hline $\mathrm{Current} \mathrm{A}$ & - & 220 & - \\
\hline Voltage, V & - & 350 & - \\
\hline Powder consumption, $\mathrm{kg} / \mathrm{h}$ & 0.65 & 15 & 0.78 \\
\hline Spraying distance, $\mathrm{mm}$ & 110 & 180 & 150 \\
\hline
\end{tabular}

The aim of the present work consisted in comparison of different high-velocity methods of spraying in producing of $\mathrm{WC}-\mathrm{Co}-\mathrm{Cr}$ coatings. Spraying was carried out by using detonation, SAGP and HVOF method.

Materials and procedure of investigations. For spraying the «Praxair» $\mathrm{WC}-\mathrm{Co}-\mathrm{Cr}$ powder (9 \% Co; 4 \% Cr; $5.2 \%$ C) (grade WC$731 / 1350 \mathrm{VF}$ ) was used produced by agglomeration with subsequent sintering. The powder particles predominantly have a spherical shape. Figure 1 shows the appearance of the powder.

The characteristics of powder $\mathrm{WC}-9 \mathrm{Co}-4 \mathrm{Cr}$ are the following: size of particles is $10-38 \mu \mathrm{m}$; fluidity is $18 \mathrm{~s}$; bulk density is $4.6 \mathrm{~g} / \mathrm{cm}^{3}$. The detonation spraying was carried out in installation Perun-S, SAGP - in installation Kiev-S, and HVOF - in installation HIPOTET 2700M. In Table 1 the parameters of spraying of the $\mathrm{WC}-$ $9 \mathrm{Co}-4 \mathrm{Cr}$ powder coatings are shown.

To carry out the metallographic examinations the coatings were sprayed on the specimens of steel St3, to determine the adhesive strength on the specimens of steel 30KhGSN2MA and titanium alloy VT22. The roughness of coatings after spraying was determined using the profilograph-profilometer. In carrying out the investigations on microstructure, microhardness and porosity of coatings the complex procedure was used, including metallography: optical microscope «Neophot-32» with the device for digital photography; for durometric analysis, durometer PMT-3 at load of $50 \mathrm{~g}$ was used. Measurements of microhardness were carried out across the whole section of coatings ( 50 measurements for each type of coating). The determination of porosity of the coatings was carried out by the analysis of images consisting in determination of the area of detected pores relatively to the whole area of the coating section. The manufacture of sections was carried out according to standard procedures.

Results of investigations. As a result of powder $\mathrm{WC}-9 \mathrm{Co}-4 \mathrm{Cr}$ spraying using high-velocity methods at the given modes, the coatings with a dense structure without cracks and fractures tightly adjacent to the base were produced. Figure 2 shows microstructure of the produced coatings $200-400 \mu \mathrm{m}$ thick.

Roughness $R_{a}$ of the sprayed coatings at detonation GTS method is 6.15, at SAGP -5.40 and at $\mathrm{HVOF}-6.75 \mu \mathrm{m}$.

The coatings produced using SAGP and HVOF methods have the same microstructure consisting of tungsten carbide particles uniformly distributed in $\mathrm{Co}^{-} \mathrm{Cr}$ matrix. The microhardness 


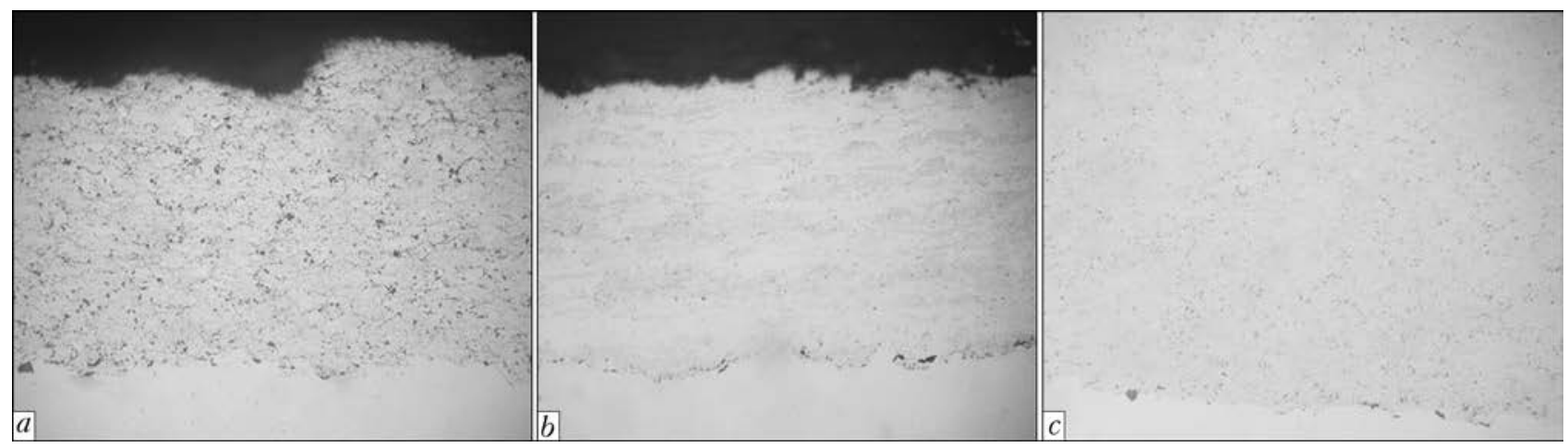

Figure 2. Microstructure $(\times 200)$ of $\mathrm{WC}-9 \mathrm{Co}-4 \mathrm{Cr}$ coatings produced using detonation $(a)$, SAGP $(b)$ and HVOF $(c)$ spraying

is $H V-0.0511 \pm 1.3 \mathrm{GPa}$ for HVOF-sprayed coatings and $H V 0.05$ is $11.7 \pm 1.7 \mathrm{GPa}$ for SAGPsprayed coatings. The porosity of coatings is less than $1 \%$.

The coating produced by detonation spraying has a lamellar structure composed of $\mathrm{Co}^{-} \mathrm{Cr}$ matrix, inclusions of tungsten carbide and oxide interlayers. The oxide content in the coating is about $5 \%$. The microhardness of the coating $H V 0.05$ is $8.5 \pm 1.2 \mathrm{GPa}$. The porosity of the coating is less than $1 \%$.

As is seen from the results, the microhardness of detonation coating is about $3 \mathrm{GPa}$ lower than that of the coatings produced by other methods due to application of oxidizing environment of detonation products of oxygen-propane-butane mixture during spraying, resulting in a more intensive interaction of WC with oxygen. This results in a partial loss of carbon and conversion of $\mathrm{WC}$ into $\mathrm{W}_{2} \mathrm{C}$, which has a lower hardness. The presence of oxides in the coating is also resulted by this.

The adhesion strength of coating $\mathrm{WC}^{-} 9 \mathrm{Co}^{-}$ $4 \mathrm{Cr}$, produced by HVOF method, was studied according to the adhesive method with testing on normal detachment of ISO 14916:1999 using adhesive VK-27 with tensile strength of $50 \mathrm{MPa}$. It was established that the adhesive strength of the coating of powder $\mathrm{WC}-9 \mathrm{Co}-4 \mathrm{Cr}$ with steel $30 \mathrm{KhGSN2MA}$ and titanium alloy VT-22 is more than $50 \mathrm{MPa}$ (in both cases the detachment occurred along the adhesive).

In Table 2 the summary results of the properties of coatings of $\mathrm{WC}-9 \mathrm{Co}-4 \mathrm{Cr}$ powder are shown produced by high-velocity spraying method. For comparison the properties of the coating of galvanic chromium are given.

\section{Conclusions}

1. Microstructure of $\mathrm{WC}-9 \mathrm{Co}-4 \mathrm{Cr}$ coatings produced using GTS high-velocity methods, represents the tungsten carbide particles uniformly distributed in $\mathrm{Co}-\mathrm{Cr}-$ matrix. The porosity of the
Table 2. Properties of coatings of $\mathrm{WC}-9 \mathrm{Co}-4 \mathrm{Cr}$, produced by high-velocity spraying method, and galvanic chromium coating

\begin{tabular}{||l|c|c|c||}
\hline \multicolumn{1}{|c|}{ Spraying method } & $\begin{array}{c}\text { Microhardness } \\
H V, \mathrm{GPa}\end{array}$ & Porosity, \% & $\begin{array}{c}\text { Adhesion } \\
\text { strength, } \\
\mathrm{MPa}\end{array}$ \\
\hline Detonation & $8.5 \pm 1.2$ & $<1$ & - \\
\hline Supersonic plasma & $11.7 \pm 1.7$ & $<1$ & - \\
\hline HVOF & $11 \pm 1.3$ & $<1$ & $>50$ \\
\hline Galvanic chrome-plating & $7.5 \pm 12$ & $3-20$ & $20-25$ \\
\hline
\end{tabular}

coatings is less than $1 \%$. In the structure of coating produced by detonation method the oxide interlayers are present (about $5 \%$ ).

2. Microhardness of $\mathrm{WC}-9 \mathrm{Co}-4 \mathrm{Cr}$ coatings produced by HVOF and SAGP method is 11.0$11.7 \mathrm{GPa}$; the microhardness of detonation coating is $8.5 \mathrm{GPa}$.

3. Decreased microhardness of detonation coating (approximately by $3 \mathrm{GPa}$ ) and presence of oxide interlayers in the microstructure are connected with the use of oxidizing environment of the detonation products of oxygen-propane-butane mixture during spraying, which leads to the development of oxidation processes of the sprayed material and, as a result, to partial loss of carbon and oxidation of matrix material.

4. Due to high hardness of $\mathrm{WC}-9 \mathrm{Co}-4 \mathrm{Cr}$ coatings produced using the HVOF and SAGP methods (11.0-11.7 GPa), in combination with a low porosity of less than $1 \%$, adhesion strength of more than $50 \mathrm{MPa}$ and environmentally friendly process of GTS technology, represent an alternative to the application of coatings, of galvanic chromium. Among the investigated GTS methods of $\mathrm{WC}-9 \mathrm{Co}-4 \mathrm{Cr}$ coatings SAGP spraying has the highest efficiency $(15 \mathrm{~kg} / \mathrm{h})$.

1. Borisov, Yu.S., Petrov, S.V. (1995) Application of supersonic jets in technology of thermal spraying. Avtomatich. Svarka, 1, 41-44.

2. Borisov, Yu.S., Kharlamov, Yu.A., Sidorenko, S.L. et al. (1987) Thermal coatings of powder materials: Refer. Book. Kiev: Naukova Dumka. 
3. Chivavibul, P., Watanabe, M., Kuroda, S. (2008) Development of WC-Co coatings deposited by warm spray process. J. Thermal Spray Technology, $17(5 / 6), 750-756$.

4. http:/ /www.tecnospray.net/download/HCST/ AMPERITBrochure.pdf AMPERIT Thermal Spray Powders

5. http://www.fisherproductsllc.com/pdf/Powder-Br ochure.pdf Praxair Surface Technology, Powder Technology Catalog

6. Shtertser, A.A., Smurov, I.Yu., Ulianitsky, V.Yu. et al. (2008) Comparative analysis of tribological properties of cermet detonation sprayed coatings. In: Proc. of ITSC (Maastricht, Netherlands, June 2-4, 2008), 125-131

7. Knapp, J.K., Nitta, H. (1997) Fine-particle slurry wear resistance of selected tungsten carbide thermal spray coatings. Tribology Int., 30(3), 225-234.

8. Du, L., Xub, B., Dong, S. (2008) Sliding wear behavior of the supersonic plasma sprayed $\mathrm{WC}-\mathrm{Co}$ coating in oil containing sand. Surface and Coatings Technology, 202(15), 3709-3714.

9. Ma, S., Li, C., Ye, X. (2005) Microstructure and properties of nanostructured WC/Co coating deposited by supersonic plasma spraying. In: Proc. of ITSC (Basel, Switzerland, 2-4 May, 2005), 794797.

10. Matthaeus, G., Brandl, W., Secosan, I.F. (2008) Standard HVOF process compared to the HVOF process for internal coating with fine powders. In: Proc. of ITSC (Maastricht, Netherlands, June 2-4, 2008), 473-476.

11. Kirsten, A., Oechsle, M., Moll, R.F. (2005) Carbide containing materials for hard chromium replacement by HVOF-spraying. In: Proc. of ITSC (Basel, Switzerland, 2-4 May, 2005), 957-962.

12. Legg, K.O., Graham, M., Chang, P. (1996) The replacement of electroplating. Surface and Coatings Technology, 81(1), 99-105.

13. Murthy, J.K.M., Venkataraman, B. (2006) Abrasive wear behavior of $\mathrm{WC}-\mathrm{Co}-\mathrm{Cr}$ and $\mathrm{Cr}_{3} \mathrm{C}_{2}-20(\mathrm{NiCr})$ deposited by HVOF and detonation spray processes. Ibid., 200(8), 2642-2652.

14. Bobzin, K., Kopp, N., Warda, T. (2013) Investigation and characterization of $\mathrm{HVOF} \mathrm{WC}-\mathrm{Co}^{-} \mathrm{Cr}$ coatings and comparison to galvanic hard chrome coatings. In: Proc. of ITSC (Busan, South Korea, May 13-15, 2013), 389-394.

15. Bolleli, G., Giovanardi, R., (2006) Corrosion resistance of HVOF sprayed coatings for hard chrome replacement. Corrosion Sci., 48(11), 3375-3397.

16. Peter, F. (2005) Ruggiero tungsten carbide coatings replace chromium. Advanced Materials and Processes, 7, 39-40.

Received 26.11.2015 